\title{
Ahuianime: las seductoras del mundo nahua prehispánico
}

\author{
Miriam LóPEZ HeRnÁNDEZ \\ Posgrado del Instituto de Investigaciones Antropológicas, Universidad Nacional Autónoma de México \\ mirlop@yahoo.com
}

Recibido: 10 de febrero de 2011

Aceptado: 11 de abril de 2011

\section{RESUMEN}

El objetivo del artículo es estudiar la prostitución entre los antiguos nahuas. A partir de los términos utilizados para nombrar a las mujeres que se dedicaban a esta actividad, los huehuetlatolli (discursos morales), los testimonios sobre su participación en fiestas y como acompañantes de guerreros valientes y víctimas de sacrificio, se plantea una posición ambivalente de esta sociedad ante dicho oficio. Por un lado se vincula a las ahuianime con la recreación, la alegría, la vida desenfadada, considerando incluso su sexualidad exuberante como necesaria en el tiempo ritual; y por otro se las considera inhumanas, vanidosas e indecentes debido a que practican una vida sexual ilícita y tienen una apariencia y conducta seductoras.

Palabras clave: Sexualidad, prostitución, ahuianime, nahuas.

\section{Ahuianime: The Seductive Women of the Prehispanic Nahua World}

\begin{abstract}
The purpose of this article is to study prostitution among the ancient Nahuas. Based on the terms used in the huehuetlatolli (moral discourses) to refer to women who used to practice this activity, as well as the testimonies regarding their participation in feasts and as companions of brave warriors and sacrificial victims, an ambivalent position in this society concerning such activity is found. First of all, the ahuianime (prostitutes) are associated with recreation, enjoyment, and a carefree life, their exuberant sexuality even being necessary during religious rituals. Nonetheless, they are considered to be less than human, vain and indecent, because they practice an immoral sexual life and adopt a seductive appearance and behavior.
\end{abstract}

Key words: Sexuality, prostitution, ahuianime, Nahuas.

Sumario: 1. Términos relacionados con la prostitución. 2. Modelo de prestigio social. 3. Arreglo y adorno de las ahuianime. 4. Integración a la sociedad. 5. Xochiquetzal: patrona de las ahuianime. 6. Relación de la prostitución en el tonalpohualli. 7. Conclusiones. 8. Referencias bibliográficas.

Las ahuianime, en el mundo nahua prehispánico, eran un grupo de mujeres de distintos orígenes a quienes les estaba permitido un lenguaje no verbal -vedado para las otras mujeres-, que consistía en ciertos movimientos del cuerpo, gesticulaciones, atavíos y cosméticos propios de su oficio: la seducción. La sexualidad desbordada no les estaba prohibida e incluso se las requería en ciertas festividades y eran necesarios sus servicios para alegrar a las víctimas de sacrificio. Su integración en la sociedad se muestra en ciertas fechas y lugares pero, en los discursos morales y en algunas palabras para calificarlas, existe una actitud de rechazo y desaprobación a su comportamiento. 


\section{Términos relacionados con la prostitución}

Existen distintos términos en náhuatl dados a las prostitutas que nos permiten aproximarnos a la concepción que se tenía de las mismas. Ahuiani, «la que está alegre», era un nombre aplicado a esta clase de mujeres, posiblemente debido a que el placer sexual estaba relacionado con el gozo que los dioses proporcionaron ante las angustias derivadas de la vida cotidiana (Códice Florentino, lib. VI, cap. XVIII, traducido por López Austin 1996: I, 276; Molina 2004: sección náhuatl-español, fol. 9v; Siméon 2002: 47). A ellas, relacionadas con la sexualidad, se las asociaría con este gozo.

Asimismo, se las podría designar de esta manera debido a que se caracterizaban por reírse con cuanto hombre se toparan, particularidad que contrastaba con el ideal de la mujer íntegra a quien se le pedía que no fuera risueña (Sahagún 2002: t. II, lib. VI, cap. XIX, 561).

El calificativo ahuilnemiliztli, que tiene la misma raíz, no connotaba negatividad, a pesar de que en el Vocabulario de Molina (2004: sección náhuatl-español, fol. 9v) se traduzca como «vida en vano»; yo lo traduzco como «vida contenta».

Alonso de Molina (2004: sección náhuatl-español, fol. 50r) presenta el concepto maauiltia, «ramera», en seguida aparece el término maauiltiani, que traduce como «puta honesta». ¿A qué se deberá la diferencia? ¿Cuál será el significado de «puta honesta»? Contamos con varios elementos para sustentar esta diferenciación.

Cuadro 1: Términos relacionados con la prostitución

\begin{tabular}{|c|c|c|}
\hline Náhuatl & Español & Análisis \\
\hline $\begin{array}{l}\text { Ahuiani/ auiani } \\
\text { Pl. ahuianime }\end{array}$ & $\begin{array}{l}\text { Puta o mala mujer (Molina 2004: secc. n-e, fol. } \\
\text { 9v) } \\
\text { Impúdica, deshonesta, mujer pública (Siméon } \\
\text { 2002: 47) }\end{array}$ & $\begin{array}{l}\text { Ahuia-ni/auia-ni* } \\
\text { 3Sg-Sust con valor verbal-Ag }{ }^{* *} \\
\text { Ahuia/auia: alegrarse } \\
\text { "la que está alegre" }\end{array}$ \\
\hline Ahuilnemilitztli & Vida en vano (Molina 2004: secc. $n-e$, fol. 9v) & $\begin{array}{l}\text { Ahuilnemi-liztli } \\
\text { Ahuilnemi: vivir alegre } \\
\text { liztli: evento } \\
\text { "vida contenta" }\end{array}$ \\
\hline Ahuilnenqui & $\begin{array}{l}\text { Persona carnal y lujuriosa (Molina 2004: secc. } \\
\text { n-e, fol. 9v) } \\
\text { Vicioso, carnal, libertino (Siméon 2002: 48) }\end{array}$ & $\begin{array}{l}\text { Ahuilnen-qui } \\
\text { Ahuilnemi: vivir alegre } \\
\text { qui: Ag } \\
\text { "la que vive/anda contenta", }\end{array}$ \\
\hline Apinauani cihuatl & $\begin{array}{l}\text { Mujer deshonesta (Molina 2004: secc. n-e, fol. } \\
\text { 8v) } \\
\text { Mujer de malas costumbres (Siméon 2002: 33) }\end{array}$ & $\begin{array}{l}\text { Apinahuani cihuatl } \\
\text { Desvergonzada mujer } \\
\text { "mujer sin vergüenza" }\end{array}$ \\
\hline Aoccan ca iyollo & $\begin{array}{l}\text { En ningún lugar está su corazón. Mujer disoluta } \\
\text { (López Austin 1996: II, 228) }\end{array}$ & $\begin{array}{l}\text { Aoccan: ya en ninguna parte } \\
\text { ca: estar } \\
\text { iyollo: su corazón } \\
\text { "ya no está en ninguna parte su } \\
\text { corazón" }\end{array}$ \\
\hline
\end{tabular}




\begin{tabular}{|c|c|c|}
\hline $\begin{array}{l}\text { Aocmo tlalia } \\
\text { iyollo }\end{array}$ & $\begin{array}{l}\text { Ya no asienta su corazón. Mujer disoluta } \\
\text { (López Austin 1996: II, 228) }\end{array}$ & $\begin{array}{l}\text { Aoc: ya no } \\
\text { mo tlalia: se asienta } \\
\text { iyollo: su corazón } \\
\text { "ya no se asienta su corazón" }\end{array}$ \\
\hline Aquetzca cihuatl & $\begin{array}{l}\text { Mujer deshonesta y sin vergüenza (Molina } \\
\text { 2004: secc. n-e, fol. } 7 \mathrm{r} \text { ) } \\
\text { Mujer desvergonzada, impúdica (Siméon 2002: } \\
\text { 34) }\end{array}$ & $\begin{array}{l}\text { Aquetzca cihuatl } \\
\text { Aquetza: levantar la cabeza } \\
\text { cihuatl: mujer } \\
\text { "mujer que levanta la cabeza" } \\
\text { (altiva) }\end{array}$ \\
\hline Cihиасиесиесh & $\begin{array}{l}\text { Mujer deshonesta y desvergonzada (Molina } \\
\text { 2004: secc. n-e, fol. 22v) }\end{array}$ & $\begin{array}{l}\text { Cihua: } \text { mujer } \\
\text { cuecuech: osada, desvergonza- } \\
\text { da, imprudente } \\
\text { "mujer osada, desvergonzada o } \\
\text { imprudente" } \\
\text { cuecuech: menear o mover }\end{array}$ \\
\hline Maauiltia & $\begin{array}{l}\text { Ramera (Molina 2004: secc. n-e, fol. 50r) } \\
\text { Cortesana, prostituta (Siméon 2002: 241) }\end{array}$ & $\begin{array}{l}\text { M-aauiltia } \\
\text { aauil: Hace diversas cosas } \\
\text { para divertirse. Reduplicación. } \\
\text { Causativo } \\
\text { "se divierte, se explaya, lleva } \\
\text { una vida alegre" }\end{array}$ \\
\hline Maauiltiani & $\begin{array}{l}\text { Puta honesta (Molina 2004: secc. n-e, fol. 50r) } \\
\text { Cortesana, prostituta (Siméon 2002: 241) }\end{array}$ & $\begin{array}{l}\text { M-aaultia-ni } \\
\text { "la/el que se divierte, la/el que } \\
\text { se recrea" }\end{array}$ \\
\hline Maqui & $\begin{array}{l}\text { "las entremetidas" } \\
\text { (Torquemada 1975: t. III, lib. X, cap. XXXV, } \\
\text { 427). }\end{array}$ & $\begin{array}{l}\text { Ma-qui } \\
\text { "atrapada", relacionada con } \\
\text { ma-l-li: cautivo } \\
\text { M-aqui: la que se mete } \\
\text { aquia: entrar, contener }\end{array}$ \\
\hline Motzinnamacani & $\begin{array}{l}\text { Puta de burdel (Molina 2004: secc. n-e, fol. 61r) } \\
\text { Cortesana, mujer pública, que vende sus favores } \\
\text { (Siméon 2002: 294) }\end{array}$ & $\begin{array}{l}\text { Mo-tzin-namaca-ni } \\
\text { Refl-Sust-Verb-Ag } \\
\text { tzintli: parte baja, trasero, } \\
\text { nalga, ano } \\
\text { namaca: vender } \\
\text { "la que vende sus nalgas, el } \\
\text { ano o trasero" }\end{array}$ \\
\hline Motetlaneuhtiani & $\begin{array}{l}\text { Puta de burdel (Molina 2004: secc. n-e, fol. 60r) } \\
\text { Mujer pública, cortesana (Siméon 2002: 291) }\end{array}$ & $\begin{array}{l}\text { Mo-te-tlaneuhtia-ni } \\
\text { Refl-Obj Ind-Verb-Ag } \\
\text { te: alguien } \\
\text { tlaneuhtia: prestar } \\
\text { "La/el que se presta a alguien" }\end{array}$ \\
\hline Monamacac & $\begin{array}{l}\text { Prostituta (Florentine Codex 1950-1969: lib. X, } \\
\text { cap. XXVI, 94) } \\
\text { Se vende, que se vende a sí misma }\end{array}$ & $\begin{array}{l}\text { Mo-namaca-c } \\
\text { 3Sg-Refl-Verb-Ag } \\
\text { "la que se vende" }\end{array}$ \\
\hline $\begin{array}{l}\text { Nouiampa tla- } \\
\text { chixtinemi }\end{array}$ & $\begin{array}{l}\text { Mujer deshonesta que no guarda la vista } \\
\text { (Molina 2004: secc. n-e, fol. 74r) }\end{array}$ & $\begin{array}{l}\text { Nouiam-pa tlachixtinemi } \\
\text { Nouiam: todos lados } \\
\text { pa: Oriente } \\
\text { tlachia: mirar } \\
\text { nemi: andar, vivir } \\
\text { "anda mirando hacia todos } \\
\text { lados" }\end{array}$ \\
\hline
\end{tabular}




\begin{tabular}{|c|c|c|}
\hline Ocholo iyollo & $\begin{array}{l}\text { Huyó su corazón. Mujer disoluta } \\
\text { (López Austin 1996: II, 228) }\end{array}$ & $\begin{array}{l}\text { Ocholo iyollo } \\
\text { Ocholo: (Pret) huir, pisar, } \\
\text { brincar } \\
\text { iyollo: su corazón } \\
\text { "Brincó, huyó, pisó su cora- } \\
\text { zón" }\end{array}$ \\
\hline Auiani calli & $\begin{array}{l}\text { Casa de alegres } \\
\text { Casa de prostitución (Siméon 2002: 47) } \\
\text { Burdel, o putería (Molina 2004: secc. n-e, fol. } \\
\text { 9v) }\end{array}$ & $\begin{array}{l}\text { Auiani calli } \\
\text { Ahuia-ni/auia-ni } \\
\text { 3Sg-Sust con valor verbal-Ag } \\
\text { Ahuia/auia: alegrarse } \\
\text { "la que está alegre" } \\
\text { calli: casa } \\
\text { "Casa de la alegre/ de alegres" }\end{array}$ \\
\hline Netzincouiloyan & $\begin{array}{l}\text { Lugar donde se compran traseros } \\
\text { Burdel (Molina 2004: secc. n-e, fol. 71r) } \\
\text { Casa de libertinaje, lupanar (Siméon 2002: 342) }\end{array}$ & $\begin{array}{l}\text { Ne-tzin-coui-lo-yan } \\
\text { Refl-Ind-Sust-Verb-Pas-Loc } \\
\text { tzintli: parte baja, trasero, } \\
\text { nalga, ano } \\
\text { couia: comprar } \\
\text { "Lugar donde se compran } \\
\text { traseros, nalgas, anos" } \\
\text { "Compradero de traseros, } \\
\text { nalgas, anos" }\end{array}$ \\
\hline Netzinnamacoyan & $\begin{array}{l}\text { Lugar donde se venden traseros } \\
\text { Burdel (Molina 2004: secc. n-e, fol. 71r) } \\
\text { Casa de prostitución (Siméon 2002: 142) }\end{array}$ & $\begin{array}{l}\text { Ne-tzin-namacoyan } \\
\text { Refl-Sust-Verb-Loc } \\
\text { tzintli: parte baja, trasero, } \\
\text { nalga, ano } \\
\text { namaco: vender } \\
\text { "Lugar donde se venden trase- } \\
\text { ros, nalgas, anos" }\end{array}$ \\
\hline
\end{tabular}

\footnotetext{
* La raíz primitiva es ahuia (verbo), después se formó la raíz ahuil (sustantivo) y, más adelante, la raíz ahuiliui (verbo). Ahuia/auia: alegrarse; ahuil: la/el contento, la/el alegre; ahuiliu: encontentarse.

** Sust: sustantivo; Ag: agentivo; Sg: singular; Refl: reflexivo; Intrans: intransitivo; Verb: verbo; Caus: causativo; Obj Ind: objeto indefinido; Refl Ind: reflexivo indefinido; Pas: pasiva; Loc: locativo; Orient: orientacional.
}

Las prostitutas participaban en distintas fiestas como en Quecholli, en Tlacaxipehualiztli, Huey Tecuilhuitl, Tlaxochimaco, Ochpaniztli y Panquetzaliztli. Algunas veces sólo bailando, otras como parte de un gremio, otras acompañando a los guerreros destacados o a estudiantes, pero resulta importante su participación en fiestas agrícolas al lado de las mujeres del pueblo. Su actuación durante las fiestas principales implica sin lugar a dudas que se les atribuía un papel relevante en las actividades colectivas, prueba de su integración en la sociedad.

Sin embargo, existen otros testimonios del repudio que se las tenía, el cual estudiaremos más adelante. La explicación que nos ofrece Guilhem Olivier (2002: 29-30) ante esta aparente contradicción es la existencia de diferentes categorías de ahuiani$m e$, algunas de ellas integradas en la sociedad en el marco de instituciones específicas, y otras repudiadas y ejerciendo un oficio tolerado pero también detestado.

Otra palabra relacionada con esta práctica es maqui, de la cual se desconoce su significado. Sin embargo, Torquemada (1975: t. III, lib. X, cap. XXXV, 427; véase también Navas s/f: 171-174) nos dice que significaba «las entremetidas»; eran las 
compañeras de los soldados. Al respecto, solamente sabemos que «se aventuraban en las batallas y muchas de ellas se arrojaban a morir en ellas».

También Siméon (2002: 256) nos da ciertas pistas sobre el posible origen de la palabra. Existen tres términos que pudieran relacionarse: maquiça «escapar de un peligro, salir, librarse de un riesgo, de un mal paso»; maquiçani «que ha escapado de un peligro»; maquixtia «huir, escapar, refugiarse». Roberto Moreno (1966: 27) considera que las maqui pertenecían a un tipo de prostitución militar. Es decir que aparte de las prostitutas de los mercados existían mujeres dedicadas únicamente a atender a los soldados. Olivier (2004: 377) comenta que las maqui eran representantes de Xochiquetzal y Cihuacoatl. «Los atavíos guerreros y las actitudes viriles de las 'cortesanas' ciertamente se explican por la voluntad de reproducir la muerte mítica de esas dos divinidades»».

Al respecto, en el Códice Cospi (1967: 41, XX, lám. 25) Xochiquetzal aparece con características guerreras. Se representa con un atavío diagnóstico izquixochitl [flor preciosa, Bourreria huanita] «guirnalda hecha con flores de maíz tostado», chimalli o escudo, bandera, flechas y banda multicolor de guerra anudada a la cintura. Atavíos explicables a la luz del mito que atribuye a Xochiquetzal ser la primera mujer muerta en la guerra (Historia de los mexicanos por sus pinturas 2002: cap. VI, 39).

Por otra parte, se las conceptuaba como no humanas, pues en el pensamiento nahua se encontraban en la categoría de «amo tlacatl». Igualmente, se las señalaba como «víctima[s] para el sacrificio, esclava[s] bañada[s] para el sacrificio». De acuerdo con López Austin (1996: II, 275, nota 54), ellas frecuentemente se vendían a sí mismas como esclavas; de ahí podían pasar, por mala conducta, al baño ritual que las limpiaba de sus impurezas para ser ofrecidas como víctimas a los dioses.

Igualmente, se las imaginaba como seres que tenían dañado el corazón. De ellas se decía «en ningún lugar está contento su corazón», «ya no asienta su corazón», «huyó su corazón» [aocan ca iyollo, aocmo tlalia iyollo, ochollo iyollo] (López Austin 1982: 168).

Recordemos que en la concepción de esta cultura, los daños del corazón podían ser derivados de una conducta inmoral, principalmente en lo que se refiere a la vida sexual; asimismo, dicho estado podía llegar a provocar situaciones patológicas que condujeran al transgresor, en este caso a la mujer disoluta, a la locura relacionada con la maldad (López Austin 1996: I, 256-257, 208).

También se consideraba que tenían dañado el hígado. El calificativo eltecuetlan, que López Austin (1996: II, 274, nota 46) traduce como «decayó fuertemente el hígado», en el sentido de vanidosa, se aplicaba a estas mujeres. Se observa que el concepto refiere a la afectación del órgano. El hígado era generador de la pasión, cuya desviación hacía malvada y loca a la persona (López Austin, 1996: I, 210). De esta manera, la inmoralidad sexual y el estado de maldad podían afectar el hígado ${ }^{1}$.

Finalmente, contamos con varias palabras que señalan los lugares donde se ejercía la prostitución. Ahuiani calli, «casa de alegres»; netzincouiloyan, «lugar donde

1 La representación gráfica de ese daño se muestra con un pie pisando dicho órgano. Véase la ilustración de la prostituta en el folio 40r del Códice Florentino (1979: lib. X, cap. XV), donde un pie pisa una figura trilobular que se puede interpretar como el hígado. Agradezco a Jaime Echeverría la indicación de este dato. 
se compran traseros» y netzinnamacoyan «lugar donde se venden traseros» (Molina 2004: sección náhuatl-español, fols. 9v, 71r; Moreno 1966: 16-17).

Los términos mencionados se pueden dividir en dos grupos, unos que connotan negatividad y otros que parecen neutrales. A partir de estas palabras, se puede deducir que a las ahuianime se las consideraba tanto personas contentas como altivas, pues debido a su actividad se les permitía un arreglo personal que no era propio de las otras mujeres, por lo que no se observa vergüenza ni modestia en su andar ni en su comportamiento, cualidad que se esperaba de todas las demás mujeres.

Vale la pena señalar aquí que en algunas fuentes, en lugar de recurrir a palabras despectivas para referirse a ellas, se habla de las prostitutas como mujer de amores o de placer, lo que nos permite señalar que al igual que en el tiempo ritual, erean aceptadas en la vida cotidiana a pesar de que en los discursos se observe lo contrario, pues su existencia contradice el ideal moral de esta cultura, discurso que estudiaremos a continuación (Pomar 2000: párr. 135, 183; Relaciones Geográficas del siglo XVI: México 1986: 14).

\section{Modelo de prestigio social}

El proverbio «el buen medio es necesario» [Tlacoqualli in monequi], resume el comportamiento ideal que se esperaba del ser humano nahua; también se podía expresar como «sólo en el medio [tlanepantla] debe uno ir, debe uno vivir» (Florentine Codex 1950-1969: lib. VI, cap. XIX, 101, cap. XLI, 231). Este refrán exhortaba a la moderación en el caminar, en el vestido, el habla y la comida; también en la sexualidad (Florentine Codex 1950-1969: lib. VI, cap. XIX, 100, cap. XXII,122124; Sahagún 2002: t. II, lib. VI, cap. XIX, 560, cap. XXII, 576, 578; véase García Quintana 1974: 163).

Este modelo cultural fue erigido por los pipiltin (clase alta) aunque su aspiración se exigía a todas las clases. Del cumplimiento de dicho modelo dependería el equilibrio social y cósmico. Con respecto al ideal en la sexualidad partimos del término tlalticpacayotl «lo terrenal» (Florentine Codex 1950-1969: lib. VI, cap. XVIII, 93), «lo que pertenece a la superficie de la Tierra» ${ }^{2}$. Éste se refiere al acto sexual, el cual tiene como límite la moderación, la templanza, el equilibrio, todo exceso traerá consecuencias no deseables. Por ello, se les aconsejaba a los hijos que se mantuvieran castos pues los dioses amaban a los abstinentes (Florentine Codex 1950-1969: lib. VI, cap. XXI, 113).

«No te arrojes a la mujer como el perro se arroja a lo que ha de comer... dándote a las mujeres antes de tiempo. Aunque tengas apetito de mujer, resístete; resiste a tu corazón hasta que seas hombre perfecto y recio» (Sahagún 2002: t. II, lib. VI, cap. XXI, 574).

La contención era importante en la sexualidad para poder asegurar hijos sanos, así como para satisfacer a la mujer en el momento de casarse, de lo contrario se

2 Pablo Escalante (comunicación personal, octubre 2008) sugiere el vínculo entre este término y el petate, el cual se pone en el piso para llevar a cabo el coito. 
le amenazaba con que quedaría «desmedrado», nunca sería «perfecto hombre» y andaría «descolorido y desainado... enflaquecido» (Sahagún 2002: t. II, lib. VI, cap. XXI, 574).

Al joven que no cumplía con el ideal moral nahua se le calificaba como:

«...ebrio... impúdico, desvergonzado, excesivamente ataviado... mal hablado... envilecido, lleno de excremento, lleno de mierda, lleno de polvo, lleno de basura [impureza por transgresión sexual]... vive en el vicio» (traducción del lib. X del Códice Florentino por López Austin 1996: II, 274).

En este sentido, se creía que las prostitutas engañaban a los jóvenes para que bebieran extractos de mazacoatl, con el fin de que pudieran tener ayuntamiento con varias mujeres y varias veces con cada una. Así, aquel infeliz que caía en la trampa moriría seco y chupado (Sahagún 2002: t. II, lib. VI, cap. XXII, 579-580, lib. XI, cap. V, párr. IV, 1044; véase López Austin 1971: 143, 201). Esta amenaza es una muestra del discurso coercitivo que existía alrededor del ejercicio de la sexualidad.

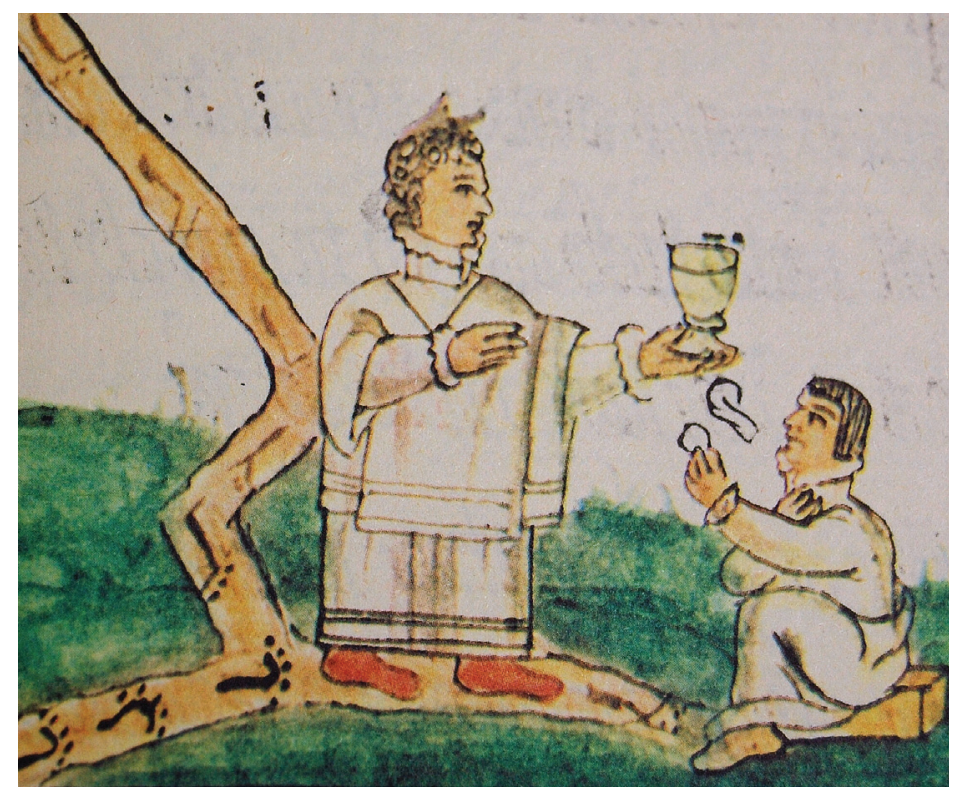

Figura 1: Las prostitutas se podían encontrar en los cruces de caminos. Éstas ofrecían de beber a los hombres, lo cual debían rechazar (Códice Florentino 1979: lib. X, cap. XXVI, fol. 70r).

La pintura del folio 70r del libro X, capítulo XXVI, del Códice Florentino (1979) ilustra bien esta advertencia. Se presenta a la prostituta [monamacac] en una intersección de caminos, lugar donde se les podía encontrar, sosteniendo una copa, la cual ofrece a un varón que está sentado y le da un pago. La comida o bebida que daban 
las prostitutas podía contener además de carne de mazacoatl, unos caracolillos que provocaban lujuria ${ }^{3}$.

El temor era que los varones se desainaban ${ }^{4}$ con estos bebedizos. Se pensaba que vaciaban la simiente de su cuerpo, se secaban, es decir, eyaculaban ininterrumpidamente hasta que encontraban la muerte (Sahagún 2002: t. II, lib. VI, cap. XXII, 579580, lib. XI, cap. V, párr. IV, 1044; véase López Austin 1971: 143, 201).

Liberar el deseo y la actividad erótica de manera inmoderada, excesiva, estaba mal visto, pues era contrario al control que uno debía tener de todos sus actos especialmente los sexuales: guardando el justo medio de las cosas. La prostituta era el factor desencadenante de la transgresión. Por otra parte era contraventor por las limitaciones que se creía tenía el semen.

De este modo, se consideraba una virtud superior resistir los embates de las tentaciones prematrimoniales, pues así se mostraba un control corporal y, por lo tanto, se mantendría su equilibrio. No obstante, también se les persuadía para que dentro del matrimonio guardaran la templanza, pues si se daban «demasiadamente a ella [la sexualidad]» se echarían a perder. «Sábete que te matas y te haces gran daño en frecuentar [tlalticpacayotl]... aunque sea con tu mujer solamente, te secarás» (Sahagún 2002: t. II, lib. VI, cap. XXI, 574; Florentine Codex 1950-1969: lib. VI, cap. XXI, 118).

Entonces, el hombre verdadero [tlacatl] sería aquel que guardara su castidad, que fuera moderado, modesto, sano, sensato, inteligente, hábil, de vida sexual correcta (López Austin 1996: I, 206). El objetivo de estas exhortaciones era concienciar al joven de su responsabilidad en el orden social.

En el caso de las jovencitas, las prohibiciones no tenían concesión pues su violación acarreaba la muerte ${ }^{5}$. Incluso la mera sospecha de comportamiento inadecuado se castigaba de manera ejemplar. Se dice que el monarca de Texcoco, Nezahualpilli, al enterarse que un joven pilli saltó la barda del recinto en donde se criaban sus hijas para conversar con una de ellas, decidió castigarla pues quedaría «muy deshonrado si a tan mal hecho no le diera su castigo», por lo que ordenó que su hija fuera ejecutada (Motolinía 1971: segunda parte, cap. III, párr. 547, 310; Mendieta 2002: t. I, cap. XXIII, 241).

A continuación revisaremos distintos aspectos de la caracterización de las prostitutas y los iremos contrastando con los discursos dados a las demás mujeres.

\footnotetext{
3 En las fuentes se mencionan varios productos afrodisiacos, entre ellos están el tlalomitl (gusanos que siempre estaban derechos y se les atribuía la cualidad de volver rígido al pene) (Sahagún 2002: t. III, lib. XI, cap. V, párr. X, 1052), la cola de tlacuache, los cuernos del escarabajo temolin, las carnes del saurio acaltetepon y del ajolote, y entre los vegetales el tlalpayatzin, el cozolmecatl y los hongos alucinógenos (López Austin 1996: I, 335).

4 Desainarse significa «perder grasa» [cihuanotza y ciuauia], Molina las interpreta como un enflaquecimiento grave que sufría el varón que tenía excesos sexuales (2004: sección náhuatl-español, fol. 22v).

5 Cabe señalar que el grado de exigencia y aplicación de amonestaciones está en relación directa con la clase social.
} 


\section{Arreglo y adorno de las ahuianime}

Según los testimonios de los informantes de Sahagún se decía que las ahuianime eran vanidosas, se ataviaban y adornaban excesivamente, se pintaban el rostro, las mejillas con axin (ungüento amarillo de la tierra) y con otros colores más, de manera que gustaban lucir «buen rostro». Igualmente se destaca que preferían llevar los cabellos sueltos y otras veces con algún peinado combinado, es decir, que a veces se arreglaban la mitad de la cabellera trenzada y la otra mitad suelta ya sea sobre la oreja o el hombro (traducción del Códice Matritense y Florentino en López Austin 1996: II, 276).

En las imágenes de estas mujeres su cabello aparece alborotado, una muestra más de la transgresión que realizaba la mujer (Códice Florentino 1979: lib. X, cap. XV, fol. 39v). Entre los nahuas no sólo se limitaban los movimientos corporales sino también el adorno, el peinado y el modo de vestir, como se mencionó anteriormente. «... No siempre desees ni quieras el adorno; no te peines continuamente; no te veas en el espejo sin cesar; no te adornes continuamente» (García Quintana 1974: 163).

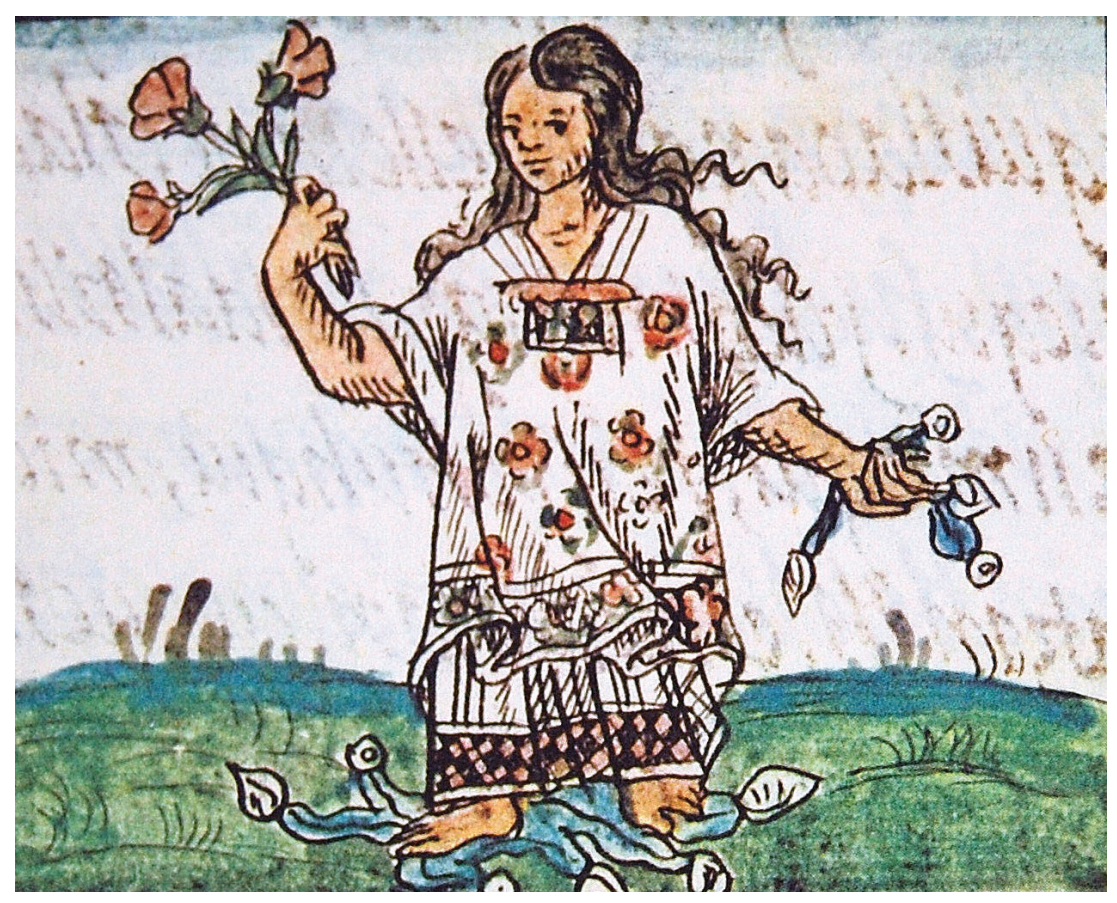

Figura 2: De las prostitutas se decía que eran vanidosas pues se ataviaban y adornaban excesivamente (Códice Florentino 1979: t. III, lib. X, cap. XV, fol. 39v). (Aunque la imagen del Códice Florentino pudo haber estado inspirada en el tema de las Gracias, del humanista renacentista Andrea Alciato en su obra Emblemata [Escalante 2008], las figuras del códice contienen la idea nahua de vincular las flores y el agua con las mujeres transgresoras. Véase López Hernández 2009: 114-115). 
Particularmente, el cabello fue considerado como una seña física que los diferenciaba de otros grupos, como los chichimecas. Se dice que durante su migración, al llegar a Tlacuchcalco, los caudillos mexicas Xiuhtzin, Calein e Itzcoatl le pidieron a su gente que no se juntaran con los chichimecas y para diferenciarse de ellos «se cortasen el cabello diferencialmente, y así fue hecho, lo cual dicen que hacían porque ansí se lo mandaba Huitzilopochtli» (Historia de los mexicanos ... 2002: cap. XII, 57).

La imagen del cabello largo y despeinado típico de los chichimecas se muestra claramente en las fuentes acolhuas: Códice Xolotl, Mapa Tlotzin y Mapa Quinatzin. Igualmente el cabello suelto y desarreglado aparece como característica de los míticos gigantes [quinametin], quienes eran señalados como homosexuales, alcohólicos, perezosos y soberbios (Durán 2002: t. I, tratado primero, cap. II, 66; Veytia 1944, t. I, lib. I, cap. III, 20; cap. XII, 105, cap. XIII, 108).

Asimismo, ésta es seña del vagabundo representado en el Códice Florentino (1979: lib. VI, cap. XLIII, fol. 201r) a quien se le propinaban insultos como «bellaco, desgreñado y sucio» (Escalante 2004: 268).

En las representaciones pictóricas de las adúlteras siendo castigadas (Códice Mapa Quinatzin, lám. 3 en Mohar 2004: 287-288; Códice Telleriano-Remensis 1964: 214215, XIX, lám. 17r; Códice Vaticano Latino A 3738 1964: 92-93, XXXVIII, lám. $25 r$ ), es de destacar que también aparecen despeinadas como evidencia de su transgresión: su inmoralidad.

En la descripción de la prostituta que encontramos en los textos de Sahagún se indica que tienen como costumbre «soltar los cabellos para más hermosura» (Sahagún 2002: t. II, lib. X, cap. XV, 891), que a su vez se asemeja a la descripción de las mujeres otomíes, pueblo criticado por los nahuas por ser lujuriosos, vestir atuendos que no correspondían a las jerarquías sociales impuestas por los mexicas, gustar del maíz tierno, no almacenar cosechas, tener reglas para el consumo del pulque más relajadas que las mexicas, fiereza de sus guerreros, y especialización en el trabajo de fibras duras (Sahagún 2002: t. II, lib. X, cap. XXIX, párr. sexto, 960-964).

De las otomíes se decía: «Y las mujeres... cuando ya mozas dexaban criar los cabellos, y los traían largos, sueltos; nunca los tocaban...» (Sahagún 2002: t. II, lib. X, cap. XXIX, párr. sexto, 961). Al contrario, el peinado de las mujeres mexicas «honestas» era el cabello partido en el centro, las mitades cruzadas en la nuca y llevadas en forma torcida o trenzada alrededor de la cabeza, hacia la frente, para terminar en dos puntas levantadas que tienen forma de cornezuelos. Su cabello recogido mostraba su conducta propia y comprometida, en la que había observancia de los límites.

Por otra parte, se señala como característico de las prostitutas sahumarse con hierbas olorosas para que su cuerpo emanara una fragancia deliciosa, perturbadora y excitante. También acostumbraban oscurecerse los dientes con grana cochinilla para llamar más la atención.

Igualmente chupaban el tzictli (derivado del chapuputli) para cuidar de la apariencia de sus dientes pues éste los limpiaba al mismo tiempo que les quitaba el mal aliento. También el tzictli lo utilizaban para llamar la atención de los posibles clientes al mascarlo (Florentine Codex 1950-1969: lib. X, cap. XXIV, 89-90). Sobre esta resina, el Códice Carolino (1967: núm. 19, 20) señala: 
«que la jovenzuelas que mastican con liviana forma ante los jóvenes al pasar dan a entender sus intenciones. Y éste es signo de atracción y así dicen moteixantia, que viene a decir: 'atrae a sí a alguno'» ${ }^{6}$.

En lo tocante a su higiene personal, afirmaban que gustaban bañarse y lavarse muy bien al igual que las mujeres honestas; la diferencia estribaba en la mesura al hacerlo y en la aplicación de los afeites. Las características anteriores contrastan con lo que se esperaba de las buenas mujeres:

«Mira, también, hija, que nunca te acontezca afeitar la cara o poner colores en ella, o en la boca, por parecer bien, porque esto es señal de mujeres mundanas, carnales. Los afeites y colores son cosas que las malas mujeres y carnales lo usan, y las desvergonzadas que ya han perdido la vergüenza y aun el seso, y andan como locas y borrachas. Éstas se llaman ahuianime» (Sahagún 2002: t. II, lib. VI, cap. XIX, 561; Florentine Codex 1950-1969, lib. VI, cap. XIX, 101).

Los gestos eran considerados altamente significativos. El movimiento de las manos era muy sugestivo debido al constreñimiento que se tenía del cuerpo en esta sociedad. Por ello en la descripción de la prostituta se enfatiza que era ruidosa e incluso indecorosa con su comunicación no verbal. De ella se decía:

«Andas llamando con los ojos [guiña los ojos a la gente, cierra el ojo a la gente], andas sonriendo a la gente [vuelve el rostro, ríe, anda riendo], andas haciendo señas con la lengua a la gente, andas silbando a la gente, andas sonando las manos (para llamar) a la gente, andas llamando a la gente con las manos... Llamas a la gente con disimulo» (traducción de los Primeros Memoriales en López Austin 1996: II, 278).

A la mujer virtuosa se le pedía que cuando fuera por la calle no mirara por aquí y por allá, ni volviera la cabeza para mirar a una parte y a otra. «Mira a todos con cara serena... de manera que ni lleves el semblante como enojada ni tampoco como risueña» (Sahagún 2002: t. II, lib. VI, cap. XIX, 561).

Ciertos movimientos externos del cuerpo eran mal vistos en esta cultura. Del andar de las prostitutas se decía que era desvergonzado, que llevaban altiva la cabeza, presumiendo, como si el ser prostituta fuera un orgullo (traducción del Códice Matritense y Florentino en López Austin 1996: II, 276). Además, se mencionaba que iban pisoteando las cosas, las arrastraban; igualmente que vagaban por los caminos, por el mercado «eres inquieta, no ves hacia tu casa» (traducción de los Primeros Memoriales en López Austin 1996: II, 278).

A la muchacha noble se le pedía que en el andar fuera honesta:

«No andes con apresuramiento ni con demasiado espacio, porque es señal de pompa andar despacio, y el andar de prisa tiene resabio de desasosiego y poco asiento. Andando llevarás un medio, que ni andes muy de prisa ni muy despacio; y cuando fuere necesario andar de prisa, hacerlo has así; por esto tienes discreción [...] Cuando fueres

6 Al igual que la ahuiani, la mujer soltera podía mascar chicle en público, indicando posiblemente que era una mujer sexualmente disponible dentro de los términos del matrimonio. A diferencia de éstas, la mujer casada tenía prohibido mascar en público. Por otra parte, el mascar en general se asociaba con los que practicaban una sexualidad en exceso, pues en los textos de fray Bernardino de Sahagún (2002: t. II, lib. X, cap. XXIV, 915; Florentine Codex 1950-1969: lib. X, cap. XXIV, 89-90) se dice que a los homosexuales se les podía identificar porque mascaban tzictli. 
por la calle o el camino no lleves inclinada mucho la cabeza y muy erguida, porque es señal de mala crianza $[. .$.$] no hagas con los pies meneo de fantasía por el camino.$ Anda con asiego [sic] y con honestidad por la calle» (Sahagún 2002: t. II, lib. VI, cap. XIX, 560-561).

Es claro que los modelos son contrarios; las prostitutas se distinguen por su conducta corporal, por su deseo de destacar, por libertinas, por vanidosas y presuntuosas, contrario al ideal de discreción que se esperaba de las demás mujeres. Se les consideraba malvadas, pervertidas, dominadoras con maleficios, vendedoras de su cuerpo, borrachas, ebrias, flojas (traducción de los Primeros Memoriales, Códice Matritense y Florentino en López Austin 1996: II, 275, 278).

Se les aplicaban fuertes calificativos como:

«Sitio de residuos, es lugar de residuos, sitio donde se muestra, residuo de anciana. Es la que se entrega sin reflexión [...] anciana lasciva, genitales lujuriosos, anciana de genitales lujuriosos, anciana fofa. Mierducha, perrilla de mierda, se echa a perder como una perra [...] Genitales lúbricos, tu lujuriosilla de los genitales. Andas palpando los genitales de la gente, andas citando a la gente para copular $[\ldots]$ vive en la inmundicia, vive en el vicio» (traducción de los Primeros Memoriales, Códice Matritense y Florentino en López Austin 1996: II, 275, 278).

Además, las prostitutas que andaban buscando clientes en las calles y barrios eran insultadas por las mujeres por temor a que sedujeran a sus esposos:

«Y así riñen las mujeres macehualtin. Se dicen: ¡ay mujerucha de por ahí! ¿Cómo me provocas? ¿Acaso tú eres mi esposo? ¿Acaso tú eres mi hombre? ¡Ay, qué mujerucha! [...] ¿Qué me dices, putilla? [...] ¿Acaso yo escandalizo sobre ti? ¿Acaso yo vivo gracias a ti? ¿Acaso tú me doblas algo? ¿Acaso yo como gracias a ti? ¡Ay, mujerucha! Greñudota, desmelenadota [...] Desvergonzada; gran malvada. Escandalosa [...] Culote agitado; culo que muere de hambre. Ay, quiere andar conociendo, por ahí, sobre los rostros de la gente. ¿Cómo se lo harás? [...] Gran malvada. Grosera. Por ahí muestra la pierna. No sea que te patee. Ciertamente no cuidas de nada, no conoces nada. ¿Acaso tú eres una mujer noble? Tú quieres cambiarte, pero no eres más que una macehualucha $[\ldots]$ ¿De dónde vienes? Vete ¿acaso es semejante a éste tu lugar? No lo es. Algo mostrarás a la gente aquí. Gorda huérfana. Malvada huérfana» (traducción de los folios 70r y v, y 71r del Códice Matritense de la Academia de la Historia en Escalante 2004: 267).

Seguramente esas mujeres eran desplazadas, huérfanas, prófugas, desprovistas de casa, que se veían en la necesidad de practicar la prostitución para sobrevivir.

Es así que en el discurso moral existió un claro repudio para esta actividad. No obstante sus movimientos del cuerpo, sus gesticulaciones, su atavío, sus cosméticos eran parte esencial de su oficio, la seducción, por lo que les era permitido ese comportamiento. Asimismo, se consideraba como una práctica que cumplía una función: salvaguardar el matrimonio y la familia.

Aunque la sexualidad desbordada no se les prohibía, pues sabemos que existían lugares para que la ejercieran, no se festejaba que esta actitud fuera generalizada en todas las mujeres pues se requerían de modelos para el sostenimiento de las instituciones sociales. 


\section{Integración en la sociedad}

Hemos tenido ya una primera visión de la prostituta que con su apariencia sofisticada y el exceso de maquillaje se distingue de la mujer recta. Sin embargo, la actitud que encontramos ante ellas en distintos momentos y lugares difiere del rechazo que permea los discursos morales. De hecho, se necesitaban de sus servicios para alegrar a víctimas de sacrificio.

En la Historia de la venida de los mexicanos... de Cristóbal del Castillo (2001: 100-101) se cuenta cómo Tetzauhteotl habló a Huitzilopochtli de su voluntad de hacer de los mexicanos un gran pueblo. Con respecto a los cautivos dice que en

«...la víspera de su muerte, velarán toda la noche, comerán, danzarán y se emborracharán; y si acaso alguno quiere acostarse con mujeres, le serán ofrecidas prostitutas, habrá muchísimas mujeres perversas, prostitutas [in azo aca quinequiz cihua cochiz macozque in ahuianime cenca miequintin onyezque iz cihuatlahueliloque in ahuianime]».

Las ahuianime eran contratadas por los señores nobles para que tuvieran relaciones sexuales con el esclavo destinado para ser inmolado en alguna de las fiestas principales. El trabajo de las mujeres públicas terminaba cuando éste moría en el altar de los sacrificios y el pago por sus servicios era el quedarse con las prendas y con todo objeto que hubiera pertenecido al esclavo (Sahagún 2002: t. I, lib. II, cap. XXIV, 191-194).

Durante el mes de Toxcatl se preparaba un mancebo representación viviente del dios Tezcatlipoca destinado al sacrificio.

«Veinte días antes que llegase esta fiesta daban a este mancebo cuatro mozas bien dispuestas y criadas para esto, con las cuales todos los veinte días tenía conversación carnal; y mudábanle el traje cuando le daban estas mozas» (Sahagún 2002: t. I, lib. II, cap. XXIV, 191-194).

Más adelante, el texto dice que

«...las cuatro doncellas que le daban por sus mujeres también eran criadas en mucho regalo. Para aquel efecto, les ponían los nombres de cuatro diosas: a una llamaban Xochiquetzal; a la otra, Xilonen, a la tercera Atlatonan; y a la cuarta Huixtocihuatl. [Todas ellas son representaciones de la deidad femenina]» (Sahagún 2002: t. I, lib. II, cap. XXIV, 191-194).

Guilhem Olivier propone que estas cuatro doncellas eran prostitutas, mujeres criadas para tal efecto (2004: 374, 408). Roberto Moreno (1966: 17, 27) opina de la misma manera, pero evoca la posibilidad de un vínculo de las cuatro jóvenes con una «prostitución sagrada».

En el caso de la veintena de Izcalli, se narra que sacrificaban a distintos esclavos en honor del dios del fuego Ixcozauhqui. A cada esclavo le daban una ahuiani quien se hacía su guardia; le divertía constantemente, le acariciaba, le decía bromas, le hacía reír, le hacía cosquillas, gozaba en su cuello, le abrazaba, le bañaba, le peinaba, arreglaba su cabello, destruía su tristeza. Y cuando era el momento de la muerte del bañado (del futuro sacrificado) la ahuani se llevaba todo. Envolvía, guardaba todas 
sus pertenencias, todo lo que había usado para vestirse y se lo llevaba (Sahagún 2002: t. I, lib. II, cap. XXXVIII, 267-268).

La función de esta prostituta es comparable al de las cuatro jóvenes que acompañaban al personificador de Tezcatlipoca. Olivier (2002: 26) reflexiona un poco más y plantea la posibilidad de que la ramera en este contexto apareciera como la vencedora del guerrero. El hecho de quedarse con los atavíos le recuerda la actitud de los ganadores en las contiendas míticas, es decir, puede interpretarse como símbolo de captura.

Por otra parte, los guerreros destacados gozaban de ciertas licencias en su comportamiento sexual: las sacerdotisas del telpochcalli tenían relaciones sexuales con ellos. Durante la fiesta de Huey Tecuilhuitl iban a bailar. A la salida las matronas las iban cuidando: «No consentían que se derramasen o que se fuesen con ningún hombre, excepto con los principales si llamaban a alguna de ellas para darlas a comer; también a las matronas que las guardaban las daban comida y mantas porque las llevaban a sus casas» (Sahagún 2002: t. I, lib. II, cap. XXVII, 217).

La solicitud se hacía con la mayor discreción, ya que de hacerlo público tanto el varón como la mujer serían severamente castigados porque para el Estado era muy importante mantener inmaculado el honor y la moral pública de los guerreros. A él le cortaban el pelo, le quitaban sus armas y atavíos y, además, le apaleaban prohibiéndole que volviera a bailar y cantar. A la mujer también se le prohibía la participación en los bailes. Por último, el guerrero era obligado a tomar por mujer a la meretriz; de esa manera, se aseguraba el sustento de la mujer, y el castigo del transgresor servía de ejemplo a los guerreros para que fueran más reservados (Sahagún 2002: t. I, lib. II, cap. XXVII, 217; véase López Austin 1985: 126-131)7.

Con respecto al pago dado a las ahuianime, en los textos nahuas se dice que se pagaban sus servicios ya sea con pertenencias -en el caso de los sacrificados- o con mantas y comida -en el caso de los guerreros-. Landa dice que las mujeres públicas en la zona maya «recibían de ellos galardón» sin especificar el tipo de pago (2003: 131). A su vez, Fernández de Oviedo (1945: t. XI, 66), entre los nicaraos, afirma que «hay mujeres públicas que ganan é se conçeden á quien las quiere por diez almendras de cacao de las que se ha dicho que es su moneda».

Olivier (2002: 26) señala que el término usado para referirse al pago de la prostituta en el texto del Códice Florentino es tlatquitl que significa «hacienda o vestido». De esta manera, dice que la mujer obtenía las propiedades del sacrificado, o bien sus vestidos y atavíos.

7 Un personaje importante para poder entablar relaciones ilícitas era la alcahueta [tetlanochili], quien también moría en caso de descubrirse su participación en un adulterio. A ella se le calificaba como «un espíritu maligno» [tlacatecolotl], se le consideraba nahual de un tzitzimitl, de un coleletli [inahual in tzitzimitl, in coleletli], excitadora de la gente [teyollocholtiani], domina con maleficios [teyolmalacachoa]... es la tendedora de trampas [tetlanahualtequiliani]» (López Austin 1996: II, 277; véase Florentine Codex 1950-1969: lib. X, cap. XV, 57). Había dos tipos de castigo para las mujeres que se dedicaban a ese oficio. A la que pertenecía a los estamentos inferiores, se le exhibía públicamente en la plaza, y ante todos los presentes «quemaban los cabellos con tea encendida, hasta que se les calentase lo vivo de la cabeza, y así afrentada y conocida por los cabellos chamuscados, se iba». La suerte de la alcahueta de los estratos principales era trágicamente diferente ya que se le ejecutaba mediante el ahorcamiento público junto con la persona que hubiera contratado sus servicios (Mendieta 2002: t. I, lib. II, cap. XXIX, 259; Torquemada 1975: t. IV, lib. XII, cap. IV, 107-108). 
Acerca del lugar de procedencia de las ahuianime, algunas seguramente fueron mexicas - pues se toleraba la prostitución de las jóvenes macehualtin (clase baja) aunque se castigaba con la muerte a la prostituta de origen noble (Veytia 2000, t. 2, fragmentos, cap. VIII, 780)-, pero otras tal vez fueron originarias de las ciudades conquistadas. Refiere la Historia Tolteca Chichimeca que Huemac sostuvo una guerra contra los nonoalcas porque su exigencia de mujeres no fue cumplida según sus deseos: «os mando que sean de caderas anchas de cuatro jemes» (1989: fol. 2r, párr. 19, 133; Garibay 2000: 467). Dicho testimonio apoyaría la creencia de que una parte de ellas pudieron haber sido esclavas o parte de los tributos de otros pueblos.

Esto nos lleva a pensar que algunas mujeres, por sus condiciones de pobreza extrema, fueron conducidas a la prostitución; otras fueron entregadas por sus familiares como tributo; otras más fueron presas de guerra y otras por voluntad propia se dedicaron a esta actividad, ya sea que fueran civiles o religiosas.

Los espacios en donde se podía encontrar a estas mujeres eran en los caminos, mercado y cuicacalli. Los informantes de Sahagún, con respecto a la prostituta decían: «andas vagando por los caminos...vagas por el mercado» (López Austin 1996: II, 278). Las encrucijadas de caminos eran espacios que se vinculaban con personas libidinosas. A dichas personas se les decía lo siguiente:

«Es mi madre y mi padre el muladar y camino orcajado [Nextepeoalli, otlamaxalli njcnonantia, njcnotatia]. Por metáfora se dezia esto de las malas mujeres que se daban por ahí a cualquiera, o de los hombre [sic] viciosos con muchas mujeres decían de los tales que eran muladar camino horcajado [que permanece en algún lugar del camino]» (Florentine Codex 1950-1969: lib. VI, cap. XLIII, 247).

Alvarado Tezozomoc (1944: cap. XLII, 182) narra respecto al mercado de Tlatelolco que unos jóvenes mexicas propiciaron un conflicto por ir a buscar mujeres «livianas» a este lugar. Contamos con otro dato respecto a Tlatelolco en donde Moctezuma ordenó que se deshiciera una ramería de mujeres públicas. Cervantes de Salazar (1985: 343) narra el episodio que tuvo lugar después de la destrucción de los dioses del Templo Mayor por Cortés:

«Disimuló [Motecuhzoma] bien el pesar que su corazón tenía por lo hecho, mandando luego secretamente deshacer una ramería de mujeres públicas que ganaban en el Tlatelolco, cada una en unas pecezuelas, como botica; serían las casas más de cuatrocientas y así las mujeres, diciendo que por los pecados públicos de aquéllas, habían los dioses permitido que viniesen a su ciudad y reino cristianos que pudiesen y mandasen más que él».

Aunque el pasaje pudiera pensarse que tiene elementos de origen español, sabemos que el número 400 se usaba en náhuatl para expresar una cantidad importante. Asimismo, en esta cultura se atribuía a las transgresiones sexuales el caos o daño que podría venir sobre toda la comunidad. El mismo pasaje lo encontramos en Torquemada (1975: t. II, lib. IV, cap. LIII, 169).

Por otra parte, existen advertencias a los jóvenes para que eviten caminar por ciertas calles, permanecer cerca del mercado, pararse en el camino, pues podrían toparse con las ahuianime o encontrarse con la mujer ajena y cometer adulterio (García Quintana 1974: 163; Olmos 1996: 120-123). 
Para la región de Michoacán se cuenta que había una mujer que ponía un «pabellón» en un mercado purépecha para recibir a «los mancebos hermosos que pasaban por el mercado y todo el día se juntaba con ellos» (Relación de Michoacán 1989: segunda parte, cap. XXII, 135).

Aunque contamos con palabras para nombrar a los prostíbulos, Motolinía (1971: segunda parte, cap. VI, párr. 573, 320-321) dice que no existían lugares especiales para la prostitución, y en otro pasaje Torquemada afirma que «no tenían casa señalada ni pública para la ejecución de su mal oficio» (1975: t. IV, lib. XII, cap. II, 101).

Otro espacio en donde las prostitutas eran visibles era en el cuicacalli (casa de canto). A los tequihuaque, guerreros valientes, se les permitía danzar con las ahuianime, pues esto formaba parte de las prerrogativas que tenían por destacarse en la milicia.

Esta casa era el lugar de encuentro de los jóvenes y también el espacio de preludio para las relaciones amorosas. Sobre estas relaciones se decía que cuando uno sentía que una mujer le miraba con interés, la llamaba

«y así acontecía andar toda la tarde con aquella muger que allí sacaba bailando de la mano poniéndole color en los labios y en los carrillos y plumas en la cabeza y joyas al cuello: cada uno festejando lo mejor que podía á aquella muger que allí se le aficionaba» (Durán 2002: t. II, tratado segundo, cap. XXI: 201).

En la fiesta de Huey Tecuilhuitl, «fiesta mayor de los señores», los que hacían el areito eran toda la gente escogida, capitanes y otros hombres valientes. Como se mencionó, estos tenían el derecho de bailar con las ahuianime. En la primera parte de la fiesta se dice que las mujeres llevaban «las caras exentas y limpias»; posiblemente no se trataría de prostitutas. En la segunda parte, después de sacrificar a la mujer que representaba a la diosa Xilonen, «llevaban teñida de color amarillo desde la barba hasta la nariz, y todas las quijadas y la frente con color colorado», lo cual es señal de que posiblemente se tratase de rameras (Sahagún 2002: t. I, lib. II, cap. XXVII, 213-220) ${ }^{8}$.

Durante Tlaxochimaco, «ofrenda de flores» se daba la convivencia de mujeres del pueblo con las ahuianime en los bailes. Es interesante que en las fiestas agrícolas se hacía caso omiso de las diferencias entre las mujeres «para destacar un símbolo, en este caso la femineidad, relacionada con la fecundidad» (Sten 1990: 89).

Igualmente, se dice que en esta festividad los valientes [otomin, cuacuachicti, tequihuaque, telpuchyaque, tiachcahuan, telpupuchti] bailaban con las mujeres públicas. «Iban asidos de las manos, una mujer entre dos hombres, y un hombre entre dos mujeres» (Sahagún 2002: t. I, lib. II, cap. XXVIII, 222). Al bailar los guerreros con las rameras, subrayan de este modo sus privilegios y estatus social.

En la celebración de Tlacaxipehualiztli, «desollamiento de hombres», igualmente participaban las ahuianime, quienes bailaban junto con las matronas. María Sten (1990: 139) expone que en las danzas en que tomaban parte los guerreros no podían participar muchachas jóvenes pues corrían el riesgo de ser seducidas por ellos. La

\footnotetext{
8 El color rojo es ambivalente. El padre, entre los consejos que da a su hija le, prohíbe usarlo; no obstante, vemos que se utilizaba en las bodas. A la novia «lávanla los cabellos, y componíanla los brazos y las piernas con pluma colorada, y poníanla en el rostro margaxita pegada» (Sahagún 2002: t. II, lib. VI, cap. XXIII, 584). Por otro lado, es adorno de prostitutas: «se ponen grana cochinilla en los dientes» (López Austin 1996: II, 276).
} 
participación de las ahuianime se explica por su función, en esa sociedad austera, de largos periodos de abstención sexual.

En Ochpaniztli, las ahuianime participaban en la batalla fingida para alegrar a la víctima de sacrificio. En esta ocasión aparecen al lado de parteras y médicas cada quien formando parte de un gremio.

Tanto en Panquetzaliztli, «erección de banderas», como en Izcalli, «crecimiento», «revivificación», las ahuianime bailaban durante 20 días mostrando la importancia de su participación en dichas celebraciones (Graulich 1999: 197; Sten 1990: 159). Por último, Torquemada (1975:t. III, lib. X, cap. XXXV, 427) dice que en Quecholli se manifestaban las prostitutas llamadas maqui, quienes se ofrecían en sacrificio.

Es así que entre los nahuas, específicamente tenochcas y tlatelolcas, la prostitución llegó a ser casi una institución de Estado, y la prostituta fue un sujeto con una función específica reconocida socialmente, lo que da la pauta para afirmar que este tipo de mujer no era despreciada en todos los contextos. Además, esta actividad sostenía a un grupo fundamental en la sociedad bélica: la de los jóvenes guerreros.

\section{Xochiquetzal: patrona de las ahuianime}

Xochiquetzal «Flor preciosa» ${ }^{9}$ en su papel de seductora es presentada como la ramera que sedujo a Topiltzin-Quetzalcoatl y precipitó su huida de Tula (Durán 2002: t. II, tratado segundo, cap. I, 23). Los Anales de Cuauhtitlan (1945: 9-10) refieren una historia que sigue el mismo patrón pero en el que se incluye la transgresión etílica ${ }^{10}$. En este caso, la protagonista del relato se llama Quetzalpetlatl.

Alva Ixtlilxochitl nos ofrece dos versiones del hecho. La que aparece en la Historia de la nación chichimeca (1997b: t. II, cap. III, 12) indica que el nombre de esta mujer era Quetzalxochitzin. En el pasaje de la Sumaria relación, el autor indica que la mujer se llamaba Xochitl (1997a: t. I, 5 Relación, 274-275).

Tanto Quetzalpetlatl, Quetzalxochitzin o Xochitl son variaciones de la seductora Xochiquetzal. Asimismo, Ruiz de Alarcón (1987: tratado VI, cap. XXXII, 221) destaca sus artes de seducción señalando que ella fue enviada para seducir a Yappan, hombre que hacía penitencia.

Otro dato relevante respecto a la naturaleza de Xochiquetzal es que presidía la ceremonia de Pillahuana entre los tlalhuicas, durante la cual niños y niñas de entre 9 y 10 años bailaban, se emborrachaban y cometían actos sexuales. Sahagún (2002: t. I, lib. I, cap. XIII, 88) menciona que la ceremonia se llevaba a cabo cada cuatro años al final del mes de Izcalli en honor a Xiuhtecuhtli. En la imagen del Códice Magliabechiano (1970: lám. 41r) se observa a la diosa frente a un niño y una niña quienes toman octli (pulque).

Asimismo, la lámina 7r del Códice Vaticano Latino A 3738 (1964: 26-27, VIII) confirma su presencia en la cuarta era, la de los toltecas. La diosa se representa des-

\footnotetext{
9 «Pluma enhiesta florida o la enhiesta florida», traducción de López Austin y García Quintana en Sahagún 2002: t. III, glosario, 1347.

10 Recordemos que el abuso del pulque y los excesos sexuales estuvieron estrechamente vinculados y fueron, seguramente, causa de muchos problemas. Véase López Hernández 2009: 120-133.
} 
cendiendo con una cuerda con flores; debajo de ella están dos hombres y una mujer, los tres tienen el torso ceñido con la cuerda trenzada ${ }^{11} \mathrm{y}$ en cada mano portan una flor y una bandera.

El significado de la cuerda se vincula con las faltas, pues de acuerdo con la lámina antes señalada, en el Sol de Tierra, Xochiquetzal desciende a la Tierra con dos cuerdas floridas engarzadas de pedernal, es decir, cuerdas de sacrificio, lo cual recuerda la falta que cometió en Tamoanchan y que introdujo males y muerte en el mundo (Códice Telleriano-Remensis 1964: 236-237, XXX, lám. 22v; Graulich 1990: 214), así como su papel de propiciadora de la caída de Tula.

Por otra parte, como patrona de las prostitutas (Sahagún 2002: t. I, lib. IV, cap. II, 353, cap. VII, 364), se señala que en Tlaxcala se le celebraba durante Quecholli. Este era el mes aplicado a los enamorados. En la fiesta se le sacrificaban, a ella y a otras divinidades, muchas doncellas en memoria de los amores.

Además, en este mes se manifestaban las mujeres públicas, las llamadas maqui, que acompañaban a los guerreros a las batallas, y se ofrecían durante la fiesta en sacrificio (Torquemada 1975: t. III, lib. X, cap. XXXV, 427). La descripción de la diosa realizada por Durán, cuyo peinado es semejante al de los guerreros [«con una coleta de hombre cercenada por la frente y por junto a los hombros»], confirma su patronato sobre dichas rameras (2002: t. II, tratado segundo, cap. XVI, 156).

\section{Relación de la prostitución en el tonalpohualli}

Los días flor eran propicios para un destino relacionado con la sexualidad ilícita. Si bien uno tenía posibilidades para evitar caer en la faceta desfavorable del signo, tendría que ser muy devoto para lograrlo. La séptima casa del signo ce ocelotl llamada chicome xochitl era ambivalente.

Las labranderas honraban este signo para que les fuera bien en su labor; sin embargo el signo era también desafortunado pues cualquier mujer labrandera que quebrantara el ayuno «le acaecía y merecía que fuese mala mujer pública». Esa influencia era de Xochiquetzal, deidad patrona de las labranderas y de las prostitutas; ella las castigaría mandándoles sarnas y otras enfermedades contagiosas (Sahagún 2002: t. I, lib. IV, cap. II, 352-353).

Por otra parte, esta caída en la prostitución se predecía también para aquellas nacidas en el cuarto signo llamado ce xochitl, pues si no realizaban penitencia serían viciosas de su cuerpo, prostitutas (Sahagún 2002: t. I, lib. IV, cap. VII, 364).

En tanto, durante la onceava trecena ozomatli se decía que nacían mujeres de condición «no muy honesta, ni casta(,) risueña(s) y muy fácil(es) de persuadir en cualquier cosa» (Durán 2002: t. II, tratado tercero, cap. II, 236). Finalmente, las nacidas en la quinceava trecena calli serían inútiles y proclives a la prostitución (Sahagún 2002: t. I, lib. IV, cap. XXVIII, 401).

11 Olivier (2004: 270) comenta que dichas cuerdas podrían simbolizar las faltas de los toltecas. 


\section{Conclusiones}

Para interpretar la visión de la prostitución en la sociedad nahua prehispánica contamos con datos diversos. En cuanto a los términos aplicados a ellas vimos que un porcentaje se relacionaba con el juego, la alegría, la vida desenfadada, la recreación, pero también había términos que las calificaban como inhumanas, malvadas, vendedoras de su cuerpo, pervertidas, vagas. Indudablemente ellas iban en contra del papel esperado para una mujer, no correspondía su actividad con la moderación y la sobriedad características del discurso moral. Asimismo, revisamos su actitud altiva, vanidosa, orgullosa, sin pudor. En la descripción de los informantes de Sahagún se las relaciona con la ebriedad, con la flojera, con la entrega a una vida sexual desenfrenada. Este retrato negativo de las ahuianime se confirma en los insultos que se proferían a una mujer extraña -posiblemente en búsqueda de algún cliente que le diera de comerque rondaba la comunidad, texto donde la influencia española parece menor.

Paralelamente tenemos los huehuetlatolli que vinculan a estas mujeres con los bebedizos que desainaban a los varones hasta morir. Dichas exhortaciones buscaban frenar el abuso en las relaciones sexuales aduciendo daños fisiológicos. Esta clase de prostitución civil existía, se toleraba, pero no se fomentaba: es la que se ejercía en los caminos, en los mercados.

Por el contrario, tenemos testimonios de un tipo de prostitución que formaba parte de las instituciones del Estado. Los favores de estas «doncellas» se otorgaban como premio a los guerreros más valientes. Participaban en las fiestas de Tlaxochimaco, Huey Tecuilhuitl, Tlacaxipehualiztli, Panquetzaliztli e Izcalli, así como acompañando a las parteras en Ochpaniztli y en Quecholli ofreciéndose para sacrificio. De manera particular, en las tres primeras celebraciones los guerreros bailaban con ellas, pues era su privilegio.

Asimismo, estudiamos que se requerían de sus servicios para acompañar a los cautivos en la víspera de su sacrificio. Se identificó una actividad comparable a este oficio en las cuatro doncellas que acompañaban al ixiptla de Tezcatlipoca y a la doncella que acompañaba al esclavo que se sacrificaría en honor de Ixcozauhqui.

Respecto a la inclinación a la prostitución, indicamos que existían ciertos días ligados con el signo xochitl en los cuales las mujeres que nacieran en ellos estarían inclinadas a la prostitución a menos que fueran penitentes y guardaran su ayuno para evitar caer en esa fase del signo. La influencia de esos días provenía de Xochiquetzal, patrona de las prostitutas y labranderas; a estas últimas las castigaba mandándoles enfermedades venéreas si no cumplían con sus obligaciones. Igualmente, señalamos el importante papel que en los mitos tiene esta diosa como propiciadora de la transgresión que trae como consecuencia la pérdida de poder y la decadencia política.

A partir de la información presentada podemos concluir que la prostitución se ejercía claramente en la sociedad nahua, aceptada al ejercerse al cobijo de los espacios estatales y con carácter de necesaria en ciertos rituales y festividades. Sin embargo, se evidenciaba un claro repudio moral al practicarse fuera de los espacios estatales. No tenemos elementos para decir si esa actividad era voluntaria o impuesta. Desconocemos el origen de las ahuianime, posiblemente eran esclavas, o cautivas, o extranjeras; lo único seguro es que no eran pipiltin debido al castigo mortal que sufrirían 
si practicaban dicha actividad. Únicamente sabemos que al nacer en cierta fecha se justificaría la caída en este oficio, aunque nunca en el discurso moral se muestra como deseable.

\section{Referencias bibliográficas}

Alva Ixtlilxochith, Fernando

1997a «Sumaria relación de todas las cosas que han sucedido en la Nueva España...», en Obras Históricas, edición de Edmundo O'Gorman, t. I, pp. 262-393. México: Instituto Mexiquense de Cultura - Instituto de Investigaciones Históricas, Universidad Nacional Autónoma de México.

$1997 b$ «Historia de la nación chichimeca», en Obras Históricas, edición de Edmundo O’Gorman, t. II, pp. 7-263. México: Instituto Mexiquense de Cultura - Instituto de Investigaciones Históricas, Universidad Nacional Autónoma de México.

Alvarado Tezozomoc, Fernando

1944 Crónica Mexicana, notas de Manuel Orozco y Berra. México: Editorial Leyenda. «Anales de Cuauhtitlan»

1945 En Códice Chimalpopoca, Anales de Cuauhtitlan y Leyenda de los Soles, Primo Feliciano Velázquez, trad., pp. 3-68. México: Imprenta Universitaria, Instituto de Historia, Universidad Nacional Autónoma de México.

Castillo, Cristóbal del

2001 Historia de la venida de los mexicanos y otros pueblos e historia de la conquista, edición de Federico Navarrete Linares. México: Consejo Nacional para la Cultura y las Artes.

Cervantes de Salazar, Francisco

1985 Crónica de la Nueva España. México: Editorial Porrúa.

«Códice Carolino»

1967 Manuscrito anónimo del siglo XVI en forma de adiciones a la primera edición del vocabulario de Molina, presentación de Ángel María Garibay K. Estudios de Cultura Náhuatl 7: 11-58.

«Códice Cospi»

1967 en Antigüedades de México, basadas en la recopilación de Lord Kingsborough, edición de José Corona Núñez, v. IV, pp. 5-49. México: Secretaría de Hacienda y Crédito Público.

Códice Florentino

Véase Sahagún, 1979.

Códice Magliabechiano

1970 Codex Magliabechiano, facsímil. Graz: Biblioteca Nazionale Centrale di Firenze - Akademische Druck Verlagsanstalt.

«Códice Telleriano-Remensis»

1964 en Antigüedades de México, basadas en la recopilación de Lord Kingsborough, edición de José Corona Núñez, v. I, pp. 151-337. México: Secretaría de Hacienda y Crédito Público. 
«Códice Vaticano Latino A 3738»

1964 en Antigüedades de México, basadas en la recopilación de Lord Kingsborough, edición de José Corona Núñez v. III, pp. 1-314. México: Secretaría de Hacienda y Crédito Público.

DurÁn, fray Diego

2002 Historia de las Indias de Nueva España e islas de tierra firme, 2 t. México: Consejo Nacional para la Cultura y las Artes.

Escalante Gonzalbo, Pablo

2004 «La cortesía, los afectos y la sexualidad», en Historia de la vida cotidiana en México, Pablo Escalante Gonzalbo, coord., t. I, pp. 261-278. México: Fondo de Cultura Económica - El Colegio de México.

2008 «Humanismo y arte cristiano-indígena. La cultura emblemática entre colegiales, artistas y otros miembros de las elites nahuas del siglo XVI», en El arte cristiano indígena del siglo XVI novohispano y sus modelos europeos, Pablo Escalante Gonzalbo, coord., pp. 9-27. Cuernavaca: Centro de Investigación y Docencia en Humanidades del Estado de Morelos.

FernÁndeZ de Oviedo y Valdés, Gonzalo

1945 Historia general y natural de las Indias. Asunción de Paraguay: Guaranda.

Florentine Codex

Véase Sahagún, 1950-1969.

García Quintana, Josefina

1974 «Exhortación de un padre a su hijo. Texto recogido por Andrés de Olmos». Estudios de Cultura Náhuatl 11: 137-182.

Garibay K., Ángel María

2000 Historia de la literatura náhuatl. México: Editorial Porrúa.

Graulich, Michel

1990 Mitos y rituales del México antiguo. España: Colegio Universitario de Ediciones Istmo.

1999 Ritos aztecas. Las fiestas de las veintenas. México: Instituto Nacional Indigenista.

«Historia de los mexicanos por sus pinturas»

2002 en Mitos e historias de los antiguos nahuas, edición de Rafael Tena, pp. 13-95. México: Consejo Nacional para la Cultura y las Artes.

Historia Tolteca-Chichimeca

1989 Paul Kirchhoff, Lina Odena Güemes y Luis Reyes García, trads. México: Centro de Investigaciones y Estudios Superiores en Antropología Social - Fondo de Cultura Económica - Gobierno del Estado de Puebla.

LANDA, fray Diego de

2003 Relación de las cosas de Yucatán, edición de María del Carmen León Cázares. México: Consejo Nacional para la Cultura y las Artes.

López Austin, Alfredo

1971 «De las plantas medicinales y de otras cosas medicinales». Estudios de Cultura Náhuatl 9: 125-230.

1982 «La sexualidad entre los antiguos nahuas», en Familia y sexualidad en Nueva España, pp. 141-176. México: SEP 80, Fondo de Cultura Económica. 
1985 Educación mexica. México: Instituto de Investigaciones Antropológicas, Universidad Nacional Autónoma de México.

1996 Cuerpo humano e ideología. Las concepciones de los antiguos nahuas, 2 v. México: Instituto de Investigaciones Antropológicas, Universidad Nacional Autónoma de México.

López Hernández, Miriam

2009 Las transgresiones sexuales entre los nahuas prehispánicos. Tesis de maestría en Antropología. México: Facultad de Filosofía y Letras, Universidad Nacional Autónoma de México.

MendietA, fray Gerónimo de

2002 Historia eclesiástica indiana, noticias del autor y de la obra por Joaquín García Icazbalceta, estudio preliminar de Antonio Rubial García, t. I. México: Consejo Nacional para la Cultura y las Artes.

Mohar Betancourt, Luz María

2004 Códice Mapa Quinatzin. Justicia y derechos humanos en el México antiguo, México: Comisión Nacional de los Derechos Humanos, Centro de Investigaciones y Estudios Superiores en Antropología Social - Miguel Ángel Porrúa.

Molina, fray Alonso de

2004 Vocabulario en lengua castellana y mexicana y mexicana y castellana, estudio preliminar de Miguel León-Portilla. México: Editorial Porrúa.

Moreno de los Arcos, Roberto

1966 «Las ahuianime». Historia Nueva 1: 13-31.

Motolinía, fray Toribio de Benavente

1971 Memoriales o Libro de las cosas de la Nueva España y de los naturales de ella, edición de Edmundo O’Gorman. México: Instituto de Investigaciones Históricas, Universidad Nacional Autónoma de México.

NAVAS, Francisco de las

s/f Cuenta antigua de los indios naturales desta Nueva España la qual guardaron y observaron hasta agora en nuestros tiempos, v. 210. México: Colección Antigua del Museo Nacional de Chapultepec.

OLIVIER, Guilhem

2002 «Entre diosas y prostitutas. Las alegres del mundo mesoamericano», en Placer, dinero y pecado. Historia de la prostitución en Colombia, Aída Martínez y Pablo Rodríguez, eds. y compls., pp. 17-37. Bogotá: Editora Aguilar.

2004 Tezcatlipoca. Burlas y metamorfosis de un dios azteca. México: Fondo de Cultura Económica.

Olmos, fray Andrés de

1996 Tratado sobre los siete pecados mortales, paleografía del texto náhuatl, edición de Georges Baudot. México: Instituto de Investigaciones Históricas, Universidad Nacional Autónoma de México.

Pomar, Juan Bautista de

2000 «Relación de Tezcoco», en Poesía náhuatl I: Romances de los señores de la Nueva España, edición de Ángel Ma Garibay K., pp. 149-219. México: Instituto de Investigaciones Históricas, Universidad Nacional Autónoma de México. 
Relación de Michoacán

1989 edición de Leoncio Cabrero. Crónicas de América 52. Madrid: Historia 16.

Relaciones geográficas del siglo XVI: México

1986 edición de René Acuña, t. III. México: Instituto de Investigaciones Antropológicas, Universidad Nacional Autónoma de México.

Ruiz de Alarcón, Hernando

1987 «Tratado de las supersticiones y costumbres gentílicas que oy viuen entre los indios naturales desta Nueua España», en El alma encantada, Anales del Museo Nacional de México, presentación de Fernando Benítez, pp. 125-223. México: Instituto Nacional Indigenista - Fondo de Cultura Económica.

SAHAGÚN, fray Bernardino de

1950-69Florentine Codex. General History of the Things of New Spain, edición de Charles E. Dibble y Arthur J. O. Anderson, 12 v. Nuevo México: The School of American Research, The University of Utah.

1979 Códice Florentino, 3 v. México: Secretaría de Gobernación.

2002 Historia general de las cosas de Nueva España, edición de Alfredo López Austin y Josefina García Quintana, 3 v. México: Consejo Nacional para la Cultura y las Artes.

SIMÉON, Rémi

2002 Diccionario de la lengua náhuatl o mexicana, Josefina Oliva, trad. México: Siglo XXI editores.

STEN, María

1990 Ponte a bailar, tú que reinas. Antropología de la danza prehispánica. México: Editorial Joaquín Mortiz.

TORquemadA, fray Juan de

1975 Monarquía Indiana, edición preparada por el Seminario para el estudio de fuentes de tradición indígena, bajo la coordinación de Miguel León-Portilla, t. II, III, IV. México: Instituto de Investigaciones Históricas, Universidad Nacional Autónoma de México.

VEYTIA, Mariano

1944 Historia antigua de México, t. I. México: Editorial Leyenda.

2000 Historia antigua de México, 2 v. México: Editorial del Valle de México. 